\title{
Effect of Monoethanolamine on Corrosion of A283 Carbon Steel in Propionic Acid Solution
}

\author{
Patomporn Lakkanasri* and Gobboon Lothongkum** \\ Department of Metallurgical Engineering, Faculty of Engineering, Chulalongkorn University, Patumwan, \\ Bangkok 10330, Thailand \\ Email:*Patomporn.L@student.chula.ac.th,**Gobboon.L@chula.ac.th
}

\begin{abstract}
This research studied the effect of monoethanolamine or MEA on corrosion of A283 carbon steels both in water and 5 vol.\% propionic acid solution at boiling point temperature of solution. MEA concentrations ranging from 30 to $90 \mathrm{wt} . \%$ in water was used. The 5 vol. $\%$ propionic acid containing around 45 and 75 wt.\% MEA additions (100:1 and 100:5) by volume in the test solution was studied. The carbon steel coupons were tested in a liquid phase, liquid and vapor phase and vapor phase. The weight losses of coupons were evaluated to calculate corrosion rate. A scanning electron microscope and X-ray diffraction were used to characterize the corrosion surface of coupons. The results showed that the corrosion rate order was in the liquid phase $>$ in the liquid and vapor phase $>$ in the vapor phase. MEA decreased the corrosion rate of A283 carbon steel both in water and 5 vol. $\%$ propionic acid solution containing around 45 and 75 wt. $\%$ MEA additions (100:1 and 100:5) by volume. MEA can be considered as corrosion inhibitor of carbon steel both in water and propionic acid solution. The formed layers of $\mathrm{FeO}(\mathrm{OH}), \mathrm{Fe}_{2} \mathrm{O}_{3}$ and $\mathrm{Fe}_{3} \mathrm{O}_{4}$ on the surface were detected to prevent a corrosion attack. The formed layer of $\mathrm{Fe}_{3} \mathrm{C}$ was also found and discussed. The more severe corrosion was in ferrite.
\end{abstract}

Keywords: Monoethanolamine, propionic acid, carbon steel, corrosion.

ENGINEERING JOURNAL Volume 23 Issue 4

Received 3 May 2019

Accepted 10 June 2019

Published 8 August 2019

Online at http://www.engj.org/

DOI:10.4186/ej.2019.23.4.183 


\section{Introduction}

In an A283 carbon steel steam system of a company, it was contaminated with acetic and propionic acids. These acids can be involved in corrosion of the carbon steel steam system [1]. Corrosion of this steam system has been controlled using a corrosion inhibitor containing monoethanolamine (MEA), having a $\mathrm{NH}_{2} \mathrm{CH}_{2} \mathrm{CH}_{2} \mathrm{OH}$ formula. MEA is an organic corrosion inhibitor, which normally can decrease the rates of cathodic and anodic reactions. Chemisorption of MEA on the metal surface may involve in decreasing corrosion of carbon steel. The chemisorption process is influenced by the chemical bond between the metal and inhibitor, and the charge transfer from the inhibitor molecule to the metal, resulting in a protective film on the metal surface $[2,3]$.

Alkanolamines are normally corrosion inhibitors in $\mathrm{CO}_{2}$ absorption systems. Examples of alkanolamines are monoethanolamine, diethanolamine, methyldiethanolamine, disopropylamine and diglycolamine. Monoethanolamine is susceptible to oxidation to amino acetic acid and has been widely used in separating $\mathrm{CO}_{2}$ from other gas systems. Copper, iodine and zinc ions were used to treat alkanolamine solution for separating $\mathrm{CO}_{2}$. They enhanced protection of metal corrosion [4-7].

Corrosions of $\mathrm{A} 106$ carbon steel in anoxic $\mathrm{CO}_{2}$ based solution with $30 \mathrm{wt} . \%$ MEA were studied at $80^{\circ} \mathrm{C}$ and $120^{\circ} \mathrm{C}$. The corrosion rate decreased with an increase in immersion duration and temperature. The formed layers of $\mathrm{Fe}_{2}(\mathrm{OH})_{2} \mathrm{CO}_{3}$ or $\mathrm{FeCO}_{3}$ on the surface were detected to prevent a corrosion attack [8].

On the other hand, corrosion of AISI 1018 carbon steel in the $\mathrm{CO}_{2}$ absorption process using MEA solution was evaluated at $80^{\circ} \mathrm{C}$. The concentration of MEA had an effect on the corrosion of carbon steel. When the MEA concentration increased from 5.0 to 7.0 and $9.0 \mathrm{kmol} / \mathrm{m}^{3}$, the corrosion rate increased from 0.55 to 0.72 and $1.06 \mathrm{mmpy}$, respectively. The increase of corrosion rates were attributed because of the increase of $\mathrm{HCO}_{3}$ - in the solution, resulting in a greater rate of iron dissolution [9].

Nevertheless, whether or not MEA increases corrosion of carbon steel is not clear. Adding 1 and 5 vol.\% MEA solutions (concentrations of about 45 and $75 \mathrm{wt} . \%$ ) to $5 \mathrm{vol} . \%$ acetic acid solution, corrosions of carbon steel in liquid, liquid and vapor and vapor phases at boiling point of solution were studied for 1 day. Carbon steel was severely corroded in the liquid phase. The corrosion rates of carbon steel decreased, especially at 5 vol. $\%$ addition [10].

The effect of MEA on carbon steel corrosion in propionic acid solution has not been found very rare in the literature review. Therefore, this work studied corrosions of A283 carbon steel in liquid, liquid and vapor and vapor phases at boiling temperature of solution for 24 hours. The test solutions were MEA concentrations in the range of $30-90 \mathrm{wt} . \%$ and $5 \mathrm{vol} . \%$ propionic acid and contained around 45 and $75 \mathrm{wt} . \%$ MEA solutions in the ratio part (100:1 and 100:5) by volume.

\section{Experiment}

\subsection{Sample Preparation}

The nominal chemical composition (wt.\%) of A283 carbon steel is shown in Table 1. All of the tested coupons with dimensions of $20 \times 50 \times 3 \mathrm{~mm}$ were prepared according to NACE TM0169-2000 [11] and ASTM G4 [12]. The coupons were ground with SiC paper down to 600 grits, ultrasonically cleaned with acetone, and kept in a silica gel 184eparation184 for 24 hours at room temperature before testing.

Table 1. Chemical composition (wt.\%) of A283 carbon steel.

\begin{tabular}{ccccccccc}
\hline Element & $\mathrm{C}$ & $\mathrm{Si}$ & $\mathrm{Mn}$ & $\mathrm{P}$ & $\mathrm{S}$ & $\mathrm{Cr}$ & $\mathrm{Mo}$ & $\mathrm{Ni}$ \\
Amount (wt.\%) & 0.056 & 0.027 & 0.274 & 0.020 & 0.013 & 0.033 & 0.003 & 0.017 \\
Element & $\mathrm{Al}$ & $\mathrm{Cu}$ & $\mathrm{Ti}$ & $\mathrm{V}$ & $\mathrm{Sn}$ & & & \\
Amount (wt.\%) & 0.032 & 0.024 & 0.001 & 0.001 & 0.001 & & & \\
\hline
\end{tabular}

\subsection{Immersion Corrosion Testing}

After measurements of the dimensions and weight, coupons were hung on a rack in liquid, liquid and vapor and vapor phases in an apparatus as shown in Fig. 1 [13]. The test solutions were MEA solutions with a 
concentration of $0,30,45,60,75$ and $90 \mathrm{wt} . \%, 5$ vol. $\%$ propionic acid solution, 5 vol. $\%$ propionic acid with around 45 and 75 wt.\% MEA solution in the ratio part (100:1 and 100:5) by volume. The test conditions were at boiling temperature of solution for 24 hours. The solution $\mathrm{pHs}$ before and after test were measured by a $\mathrm{pH}$ meter.

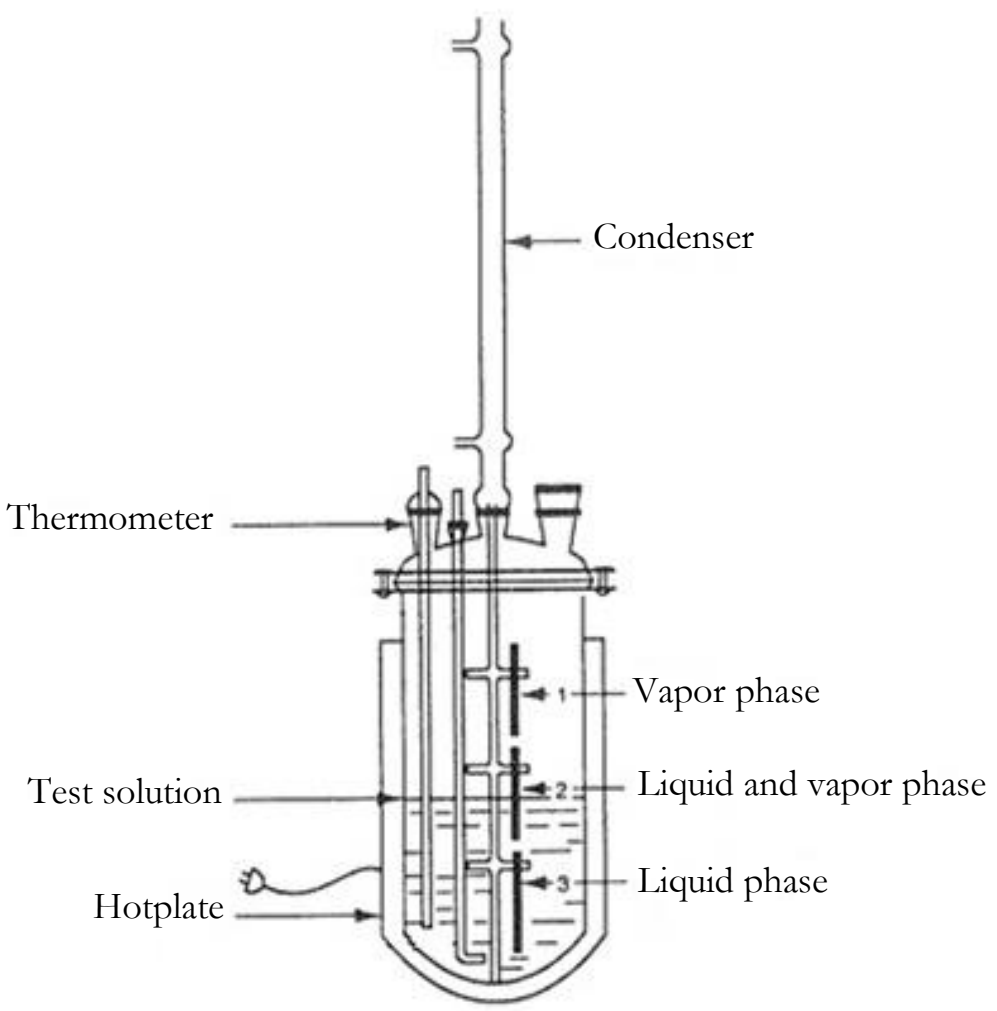

Fig. 1. Immersion corrosion testing [13].

\subsection{Cleaning Coupons after Test}

According to ASTM G1 [14], tested coupons were cleaned with solutions of concentrated $1000 \mathrm{ml}$ hydrochloric acid $(\mathrm{HCl})$ solution $+20 \mathrm{~g}$ antimony trioxide $\left(\mathrm{Sb}_{2} \mathrm{O}_{3}\right)$ and $50 \mathrm{~g}$ stannous chloride $\left(\mathrm{SnCl}_{3}\right)$ at 20 $25^{\circ} \mathrm{C}$ for $1-25$ mins. After that, they were ultrasonically cleaned with acetone, and kept in a silica gel 185eparation 185 for 24 hours.

\subsection{Characterization Methods}

Corrosion rates (CPR) were calculated according to ASTM G1 [14] from mass losses of at least three samples by Eq. (1).

$$
\mathrm{CPR}=\frac{\mathrm{KW}}{\rho \mathrm{At}}
$$

Where: $\mathrm{K}=$ a constant $\left(8.76 \times 10^{4} \mathrm{~mm} / \mathrm{y}\right), \mathrm{W}=$ mass loss in $\mathrm{g}, \varrho=$ density in $\mathrm{g} / \mathrm{cm}^{3}, \mathrm{~A}=$ area in $\mathrm{cm}^{2}$, and $\mathrm{t}$ $=$ time of exposure in hours

The corroded coupons were experimented for surface morphologies by a scanning electron microscope (SEM) and for surface composition by X-ray diffraction (XRD) with a $\mathrm{Cu} \mathrm{K} \alpha$ x-ray at the incident of 0.02 degrees.

\section{Results and Discussion}

Figure 2 shows the corrosion rates of A283 carbon steel in different concentrations of MEA solutions at boiling point temperature of solution. Adding MEA concentrations in the range of 30 to $90 \mathrm{wt} . \%$, the corrosion rates of A283 carbon steel in liquid, liquid and vapor and vapor phases decreased from about 1.71, 
$0.76,1.10 \mathrm{~mm} / \mathrm{y}$ to about $0.11,0.11$ and $0.14 \mathrm{~mm} / \mathrm{y}$, respectively. This might have been due to MEA adsorption on the metal surface resulting in a protective film. Then, the rates of cathodic and anodic reactions decreased $[15,16]$. From Fig. 2, MEA can be considered as a corrosion inhibitor. The results were similar to those of Wichaya Saihan and Siwakorn Suksawat [10], but not those of Immanuel Raj Soosaiprakasam and Amornvadee Veawab [9].

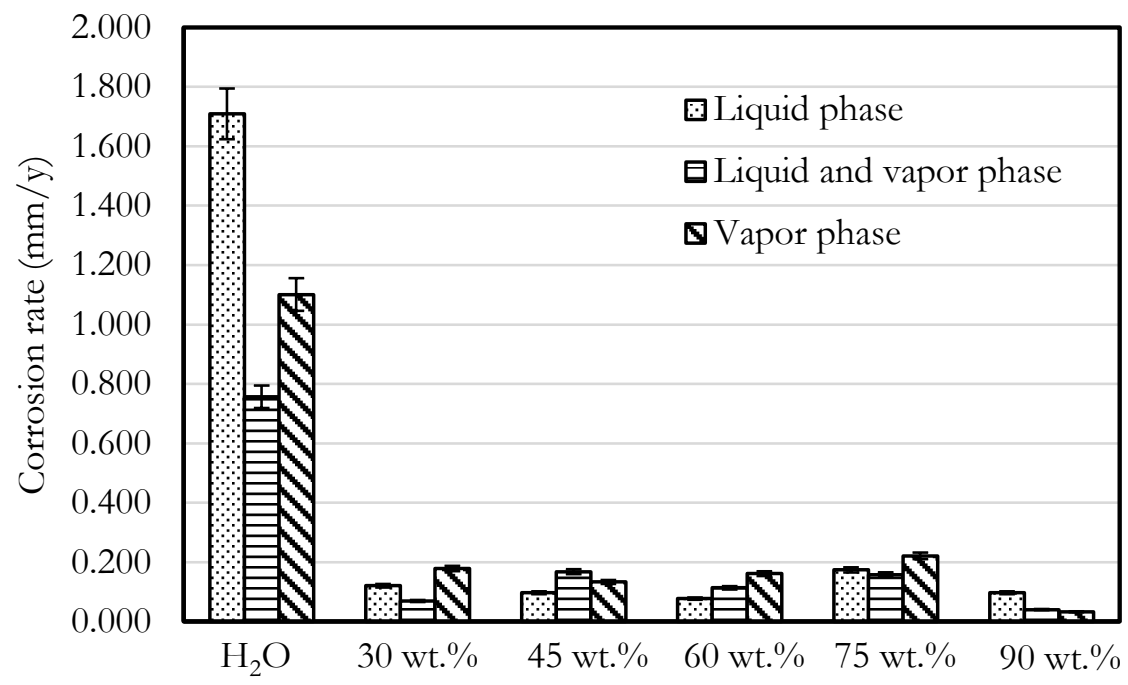

Fig. 2. Corrosion rates of A283 carbon steel in different concentration of MEA solution at boiling point temperature.

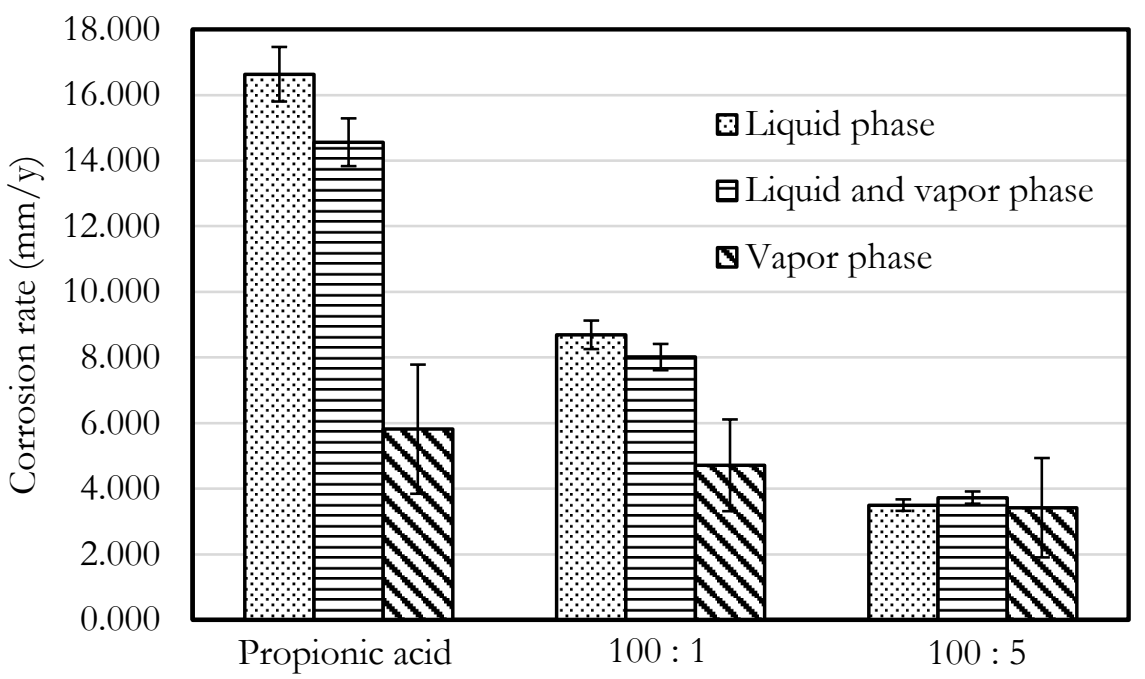

Fig. 3. Corrosion rates of A283 carbon steel in 5 vol. $\%$ propionic acid solutions with around $45 \mathrm{wt.} \%$ MEA solution at 100:1 and 100:5 additions by volume and boiling point temperature. 


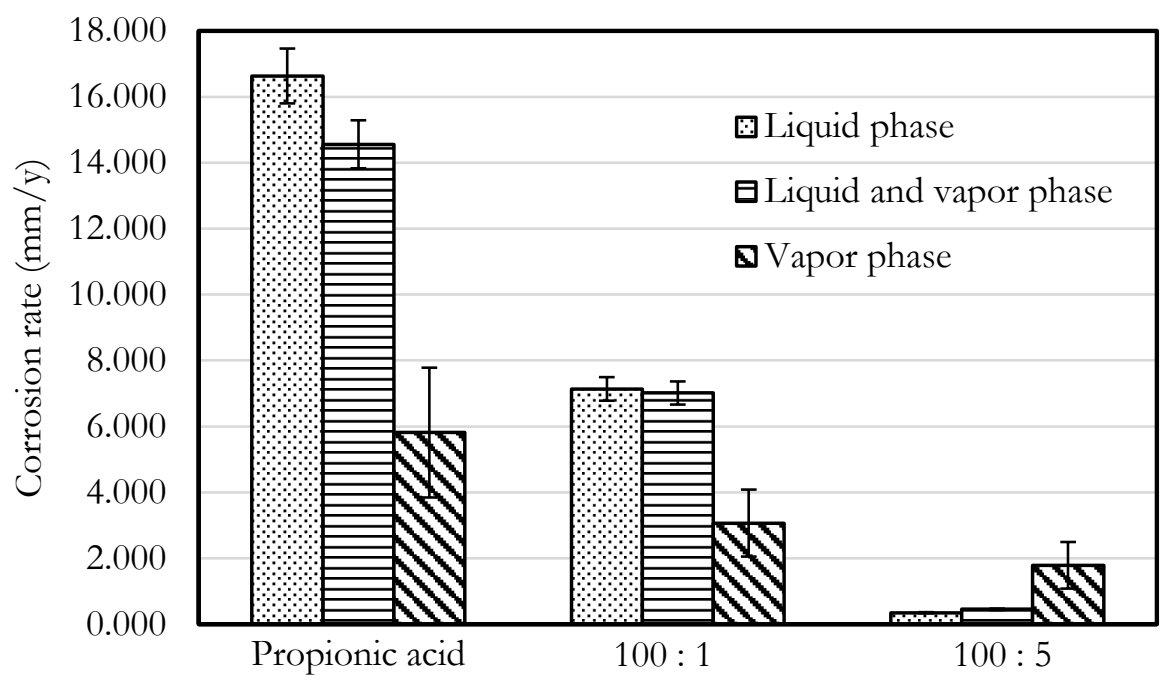

Fig. 4. Corrosion rates of A283 carbon steel in 5 vol. $\%$ propionic acid solutions with around $75 \mathrm{wt.} \%$ MEA solution at 100:1 and 100:5 additions by volume and boiling point temperature.

Figures 3 and 4 showed that carbon steel in 5 vol.\% propionic acid solution corroded in the liquid phase higher than in the liquid and vapor phase and vapor phase, respectively, because of more homogeneous solution concentration. Increase of about 45 and $75 \mathrm{wt} . \%$ MEA solutions from 0 to 100:1 and 100:5 additions by volume to the test solution, corrosion rates of A283 carbon steel in liquid, liquid and vapor and vapor phases decreased. This showed that MEA could reduce the corrosion rate of carbon steel. The solution $\mathrm{pHs}$ before and after testes were 4-6 in all additions of MEA solutions (Figs. 3 and 4), except in 100:5 additions by volume of around $75 \mathrm{wt} . \%$ MEA solutions (Fig. 4). The pHs increased from 4 before test to 10 after test. The inhibition effect of MEA on decrease of A283 corrosion rate was clear by around $75 \mathrm{wt} . \%$ MEA solution addition of 100:5 by volume in Fig. 4, because of high base solution resulting in possibly carbon steel passivity.

Figures $5 \mathrm{a}$ and $6 \mathrm{a}$ showed XRD patterns of A283 carbon steel after in liquid phase testing of 5 vol.\% propionic acid, 5 vol.\% propionic acid with around 45 and 75 wt.\% MEA additions of 100:1 and 100:5 by volume. They showed the sharp peak of Fe (ICDD 01-089-7194) for all conditions. However, zooming in 15 to 45 degree analysis (Fig. 5b-d and Fig. 6b-d), they showed some iron oxides and the $\mathrm{Fe}_{3} \mathrm{C}$ were found to form on the surface. Both in 5 vol.\% propionic acid (Figs. $5 \mathrm{~d}$ and $6 \mathrm{~d}$ ) and 5 vol. $\%$ propionic acid with around $45 \mathrm{wt} . \%$ MEA at 100:1 addition by volume in the test solution (Fig. 5c), they showed that only $\mathrm{Fe}_{3} \mathrm{C}$ (ICDD 00-034-0001) appeared on the surface. By additions of around 45 wt. \% MEA solutions at 100:5 by volume in the test solution, (Fig. 5b), the $\mathrm{Fe}_{3} \mathrm{O}_{4}$ (ICDD 01-071-6336) and $\mathrm{Fe}_{2} \mathrm{O}_{3}$ (ICDD 01-076-4579) were observed. Due to low partial pressure of $\mathrm{O}_{2}$ [17], it was thought that the $\mathrm{Fe}_{2} \mathrm{O}_{3}$ and $\mathrm{Fe}_{3} \mathrm{O}_{4}$ could not be formed but $\mathrm{Fe}_{3} \mathrm{C}$ could exist (Figs. 5c and 5, 6d). The higher concentrations of MEA could result in enough $\mathrm{O}_{2}$ for iron oxide formations (Fig. 5b). Similar results can be observed in Fig. 6b-c. The FeO(OH) (ICDD 01-081-0462), $\mathrm{Fe}_{3} \mathrm{O}_{4}$ and $\mathrm{Fe}_{2} \mathrm{O}_{3}$ were found to form on the surface, with around 75 wt.\% MEA at 100:1 additions by volume in the test solution (Fig .6c) $[18,19]$. This could be enough $\mathrm{O}_{2}$. However, increasing MEA from 100:1 to 100:5 additions by volume in the test solution, the $\mathrm{FeO}(\mathrm{OH})$ and $\mathrm{Fe}_{2} \mathrm{O}_{3}$ disappeared on the surface (Fig. 6b). Only $\mathrm{Fe}_{3} \mathrm{O}_{4}$ was found on the surface. 

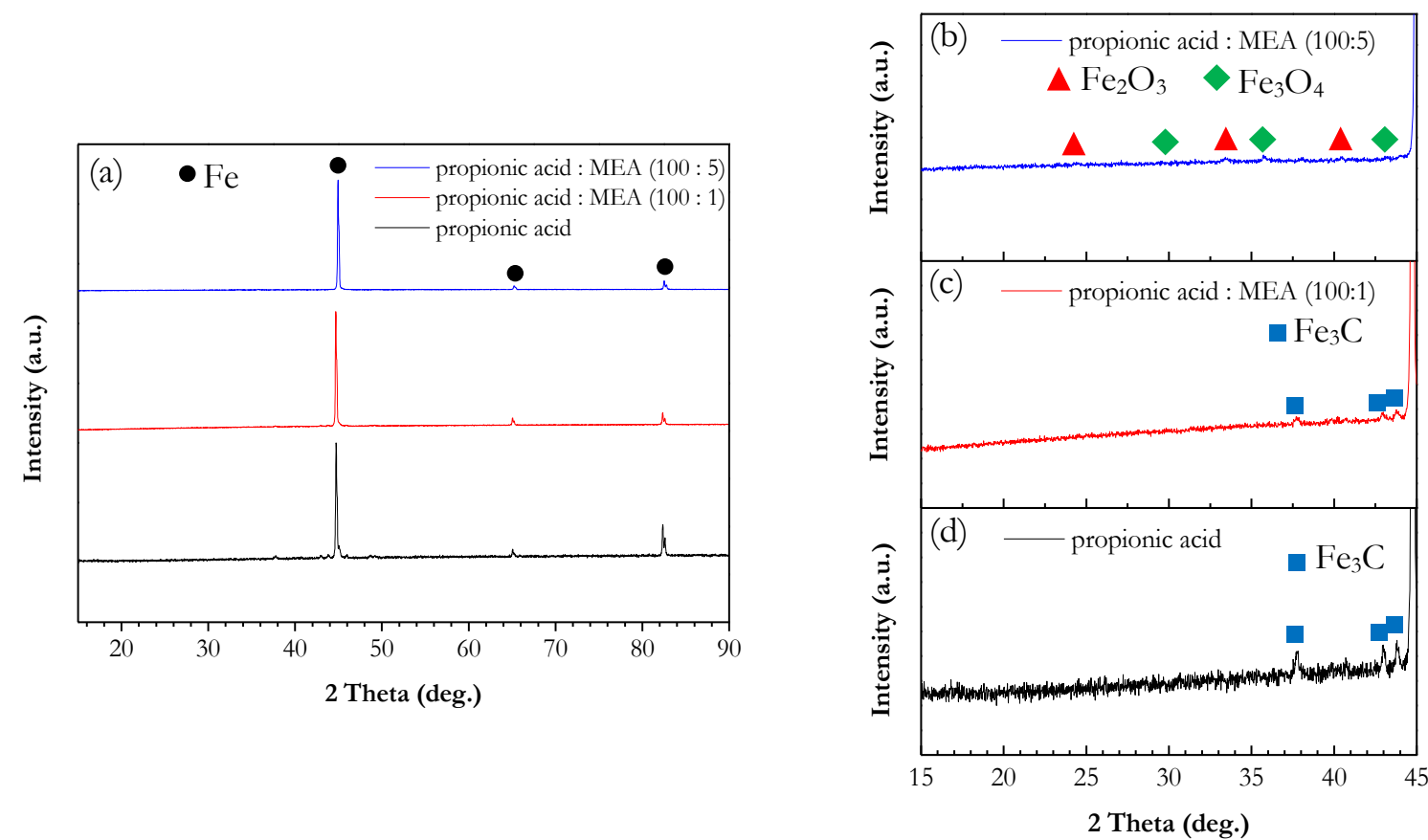

Fig. 5. XRD patterns of A283 carbon steel after in liquid phase testing of 5 vol. $\%$ propionic acid and 5 vol. $\%$ propionic acid with around $45 \mathrm{wt} . \%$ MEA additions.
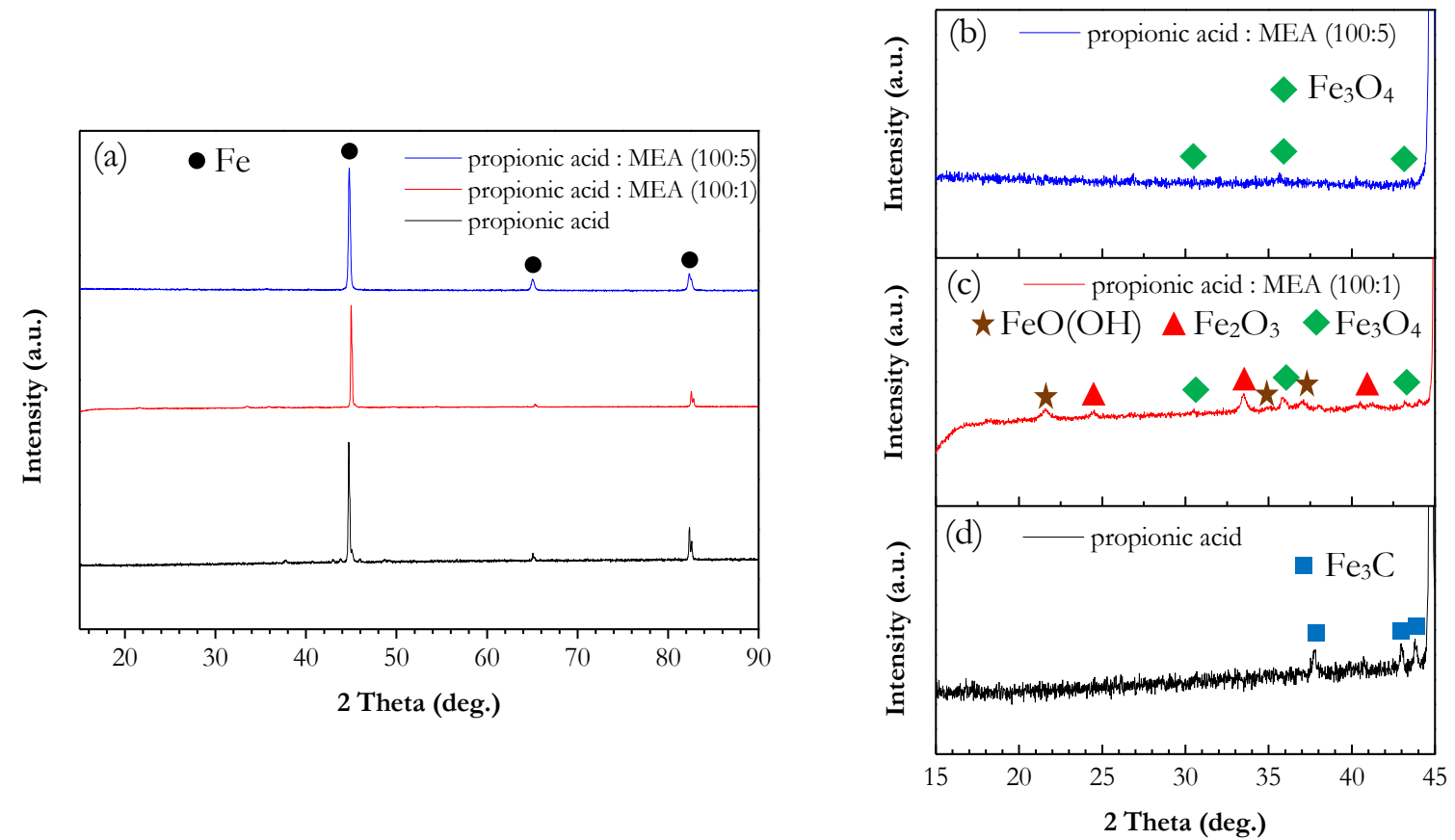

Fig. 6. XRD patterns of A283 carbon steel after in liquid phase testing of 5 vol.\% propionic acid, and 5 vol. $\%$ propionic acid with around $75 \mathrm{wt} . \%$ MEA additions. 
From literature review [16], the adsorption of MEA on the hydroxylated $\mathrm{Cr}_{2} \mathrm{O}_{3}$ surface of steel inhibited the steel corrosion. The two mechanisms of MEA effect on reduction of steel corrosion were then proposed: the adsorption of MEA and the formations of protective layers at surface of A283 carbon steel.

The adsorption of MEA on $\mathrm{Fe}_{3} \mathrm{O}_{4}$ corrosion product to inhibit Fe dissolution by water was shown as Eq. (2)-(3).

$$
\begin{aligned}
3 \mathrm{Fe}+4 \mathrm{H}_{2} \mathrm{O} & \rightarrow \mathrm{Fe}_{3} \mathrm{O}_{4}+4 \mathrm{H}_{2} \\
\mathrm{Fe}_{3} \mathrm{O}_{4}-\mathrm{m}\left(\mathrm{H}_{2} \mathrm{O}\right)+\mathrm{nMEA} & \rightarrow \mathrm{Fe}_{3} \mathrm{O}_{4}-\left(\mathrm{mH}_{2} \mathrm{O}\right)-\text { nMEA }
\end{aligned}
$$

The formations of protective layers were shown as Eq. (4)-(9).

$$
\begin{aligned}
\mathrm{Fe} & \leftrightarrow \mathrm{Fe}^{2+}+2 \mathrm{e}^{-} \\
\mathrm{OH}-\mathrm{C}_{2} \mathrm{H}_{4}-\mathrm{NH}_{2}(\mathrm{MEA})+\mathrm{H}_{2} \mathrm{O} & \leftrightarrow \mathrm{HO}-\mathrm{C}_{2} \mathrm{H}_{4}-\mathrm{NH}_{3}^{+}+\mathrm{OH}^{-} \\
\mathrm{Fe}^{2+}+2 \mathrm{OH}^{-} & \rightarrow \mathrm{Fe}(\mathrm{OH})_{2} \\
4 \mathrm{Fe}(\mathrm{OH})_{2}+\mathrm{O}_{2} & \rightarrow 4 \mathrm{FeO}(\mathrm{OH})+2 \mathrm{H}_{2} \mathrm{O} \\
2 \mathrm{FeO}(\mathrm{OH})+\mathrm{Fe}(\mathrm{OH})_{2} & \rightarrow \mathrm{Fe}_{3} \mathrm{O}_{4}+2 \mathrm{H}_{2} \mathrm{O} \\
2 \mathrm{Fe}_{3} \mathrm{O}_{4}+\mathrm{H}_{2} \mathrm{O} & \rightarrow 3 \mathrm{Fe}_{2} \mathrm{O}_{3}+\mathrm{H}_{2}
\end{aligned}
$$

The dissolution of $\mathrm{Fe}$ is usually followed Eq. (4) because of oxygen reduction in water. MEA could react with water to form $\mathrm{OH}^{-}$(Eq. (5)) [20] and then reduced dissolution of $\mathrm{Fe}$ to form $\mathrm{Fe}(\mathrm{OH})_{2}$ by Eq. (6). The formation of corrosion product $(\mathrm{FeO}(\mathrm{OH})$ ) (Fig. 6c) could be possible by Eq. (7) [21]. The $\mathrm{FeO}(\mathrm{OH})$ could be converted to $\mathrm{Fe}_{3} \mathrm{O}_{4}$ (Figs. 5b and 6b-c) followed Eq. (8) [22]. The formation of $\mathrm{Fe}_{2} \mathrm{O}_{3}$ (Figs. 5b and 6c) might be formed by the transformation of $\mathrm{Fe}_{3} \mathrm{O}_{4}$ as shown in Eq. (9) [9].

The A283 carbon steel is composed of two microstructures or phases: ferrite and pearlite (Fig. 7a). The pearlite was positioned on the grain boundary. Figure 7b-d shows the corroded phases after corrosion test in solutions of 5 vol. $\%$ propionic acid solution in liquid, vapor phases, and $5 \mathrm{vol} . \%$ propionic acid solution with around 45 wt. $\%$ MEA additions of 100:5 by volume in the liquid phase, respectively. The $\mathrm{Fe}_{3} \mathrm{C}$ was more cathodic than ferrite [23-25]. Therefore, the most corroded phases were ferrite not pearlite, because it contained $\mathrm{Fe}_{3} \mathrm{C}$ which had more corrosion resistance than ferrite. The more severe corrosion was found in ferrite, when the coupons were in liquid, as shown in Fig. 7b. By addition of MEA into solution, the corroded ferrite was decreased, as shown in Fig. 7 d.

\section{Conclusions}

Corrosion of A283 carbon steel in MEA solutions, 5 vol.\% propionic acid solution with around 45 and 75 wt. \% MEA additions of 100:1 and 100:5 by volume in the test solution at boiling temperature of solution were studied for 1 day. Based on the results, the following conclusions were obtained:

(1) MEA reduced corrosion rates of A283 carbon steel in 5 vol. \% propionic acid solution.

(2) Corrosion rates of A283 carbon steel in 5 vol.\% propionic acid solution in liquid phase were higher than in liquid and vapor and in vapor phases.

(3) In 5 vol. $\%$ propionic acid solution, by adding around $75 \mathrm{wt} \%$ MEA solutions decreased the corrosion rate of A283 carbon steel greater than by adding around $45 \mathrm{wt} . \%$ MEA solutions at the same volume addition.

(4) The formed layers of corrosion products were $\mathrm{Fe}_{3} \mathrm{C}, \mathrm{FeO}(\mathrm{OH}), \mathrm{Fe}_{2} \mathrm{O}_{3}$ and $\mathrm{Fe}_{3} \mathrm{O}_{4}$. 

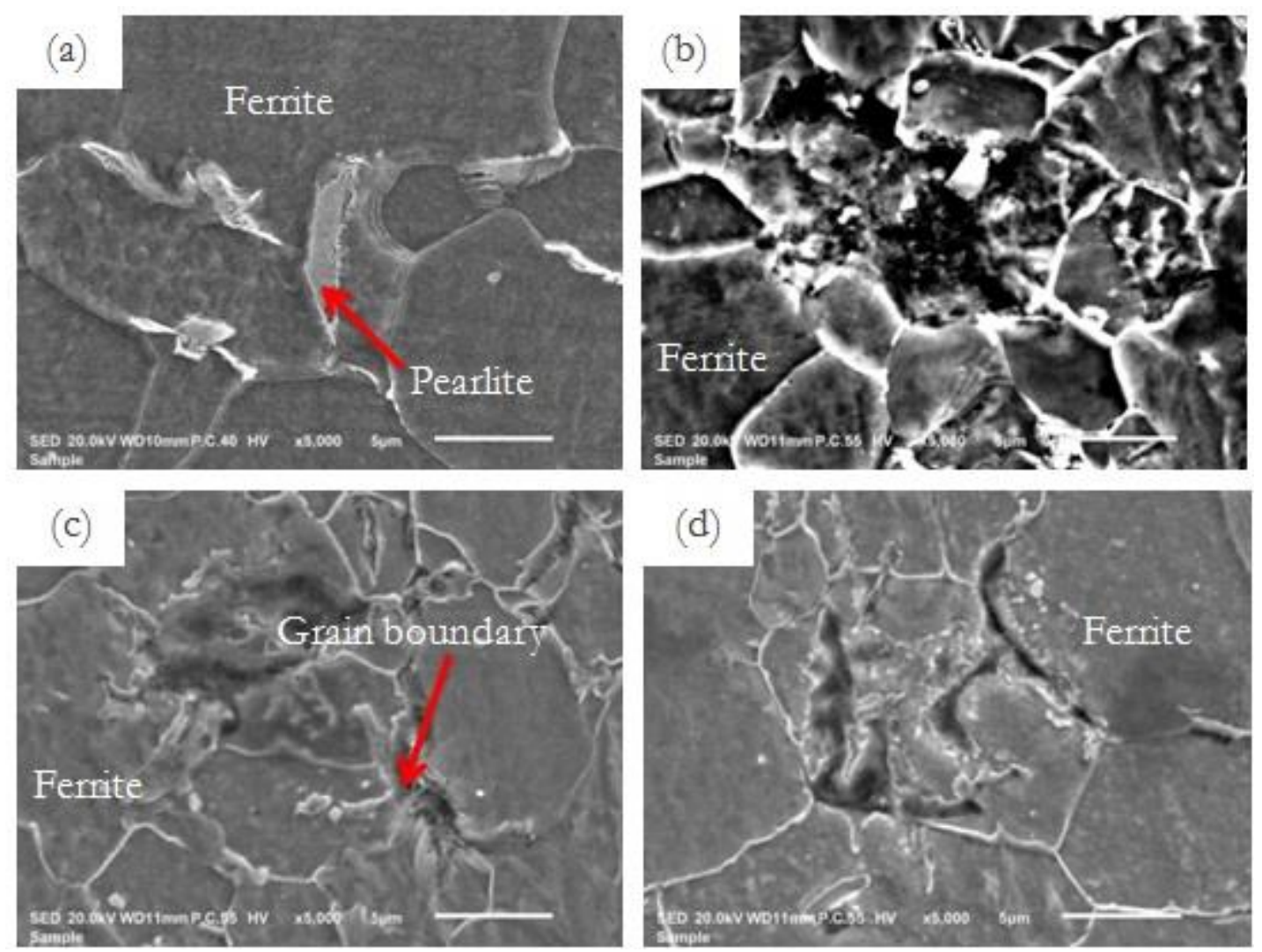

Fig. 7. SEM surface morphologies of (a) A283 carbon steel, (b) after the corrosion test of (a) in 5 vol.\% propionic acid solution in liquid phase, (c) after the corrosion test of (a) in 5 vol. \% propionic acid solution in vapor phase and (d) after the corrosion test of (a) 5 vol. $\%$ propionic acid solution with around $45 \mathrm{wt} . \%$ MEA (100:5) in the liquid phase.

\section{Acknowledgement}

The authors would like to acknowledge the Thailand Research Fund (TRF) under the university- industry collaboration project No. MSD59I0089 for their financial support.

\section{References}

[1] R. Svoboda, F. Gabrielli, H. Hehs, H.-G. Seipp, F.-U. Leidich, and B. Roberts, "Organic impurities and organic conditioning agents in the steam/water cycle: A power plant manufacturer's point of view," PowerPlant Chemistry, vol. 8, no. 8, pp. 502-509, 2006.

[2] V. S. Sastri, Green Corrosion Inbibitors. Hoboken: John Wiley \& Sons, Inc., 2011, pp. 1, 10-27, 105-115, 223-231.

[3] P. A. Schweitzer, Corrosion of Linings and Coatings Cathodic and Inbibitor Protection and Corrosion Monitoring. Taylor and Francis Group, 2007, pp. 55-65, 536-537.

[4] L. V. Minevski, "Corrosion inhibitor for alkanolamine units," U.S. Patent 6,036,888, 1999.

[5] J. A. V. Trevino, "Corrosion inhibitor for $\mathrm{CO}_{2}$ absorption process using alkanolamines," U.S. Patent 4,714,597, 1987.

[6] Bruce T. Alexander, "Stabilization of aqueous amine solutions against oxidation and corrosion in gas 190eparation processes," U.S. Patent 2,559,580, 1951.

[7] R. M. Reed, "Stabilization of monoethanolamine solutions," U.S. Patent 2,377,966, 1945.

[8] L. Zheng, N. S. Matin, J. Landon, G. A. Thomas, and K. Liu, " $\mathrm{CO}_{2}$ loading-dependent corrosion of carbon steel and formation of corrosion products in anoxic $30 \mathrm{wt} . \%$ monoethanolamine-based solutions," Corrosion Science, vol. 102, pp. 44-54, 2016. 
[9] I. R. Soosaiprakasam and A. Veawab, "Corrosion and polarization behavior of carbon steel in MEAbased $\mathrm{CO}_{2}$ capture process," International Journal of Greenhouse Gas Control, vol. 2, no. 4, pp. 553-562, 2008.

[10] W. Saihan and S. Suksawat, "A test for suitable corrosion inhibitor for carbon steel and AISI 304L stainless steel in acetic acid solution," Chulalongkorn University, Bangkok, Thailand, 2016.

[11] Standard Test Method Laboratory Corrosion Testing of Metals, NACE Standard TM0169-2000, 1995, pp. 1-10.

[12] Standard Guide for Conducting Corrosion Coupon Tests in Field Applications, ASTM G4, 1995, pp. 45-53.

[13] Standard Practice for Laboratory Immersion Corrosion Testing of Metals, ASTM G31, pp. 1-8, 1999

[14] Standard Practice for Preparing, Cleaning, and Evaluation Corrosion Test Specimens, ASTM G1, 1999, pp. 15-21.

[15] I. Jevremovic and V. Miskovic-Stankovic, "The inhibitive effect of ethanolamine on corrosion behavior of aluminium in $\mathrm{NaCl}$ solution saturated with CO2," Metallurgical and Materials Engineering, vol. 18, no. 4, pp. 241-258, 2012.

[16] A. Gouron, J. Kittel, T. de Bruin, and B. Diawara, "Density functional theory study of monoethanolamine adsorption on hydroxylated $\mathrm{Cr}_{2} \mathrm{O}_{3}$ surfaces," The Journal of Physical Chemistry $C$, vol. 119, no. 40, pp. 22889-22898, 2015.

[17] D.-Y. Kim, Y.-U. Heo, and Y. Sasaki, "Cementite formation from magnetite under high pressure conditions," ISIJ International, vol. 53, no. 6, pp. 950-957, 2013.

[18] M. Cohen, "The formation and properties of passive films on iron," Canadian Journal of Chemistry, vol. 37, no. 1, pp. 286-291, 1959.

[19] Y.-S. Kim and J.-G. Kim, "Corrosion behavior of pipeline carbon steel under different iron oxide deposits in the district heating systems," Metals, vol. 7, no. 5, pp. 1-20, 2017.

[20] M. A. Scheiman, "A review of monoethanolamine chemistry," U.S. Naval Research Laboratory, pp. 151, 1962.

[21] A. K. De, Environmental Chemistry. New Age International (P) Ltd., 2003, pp. 155-157.

[22] N. Mizutani, T. Iwasaki, S. Watano, T. Yanagida, H. Tanaka, and T. Kawai, "Effect of ferrous/ferric ions molar ratio on reaction mechanism for hydrothermal synthesis of magnetite nanoparticles," Bulletin of Materials Science, vol. 31, no. 5, pp. 713-717, 2008.

[23] D. N. Staicopolus, "The role of cementite in the acidic corrosion of steel," Journal of the Electrochemical Society, vol. 110, no. 11, pp. 1121-1124, 1963.

[24] J. J. Moore, Chemical Metallurgy. Butterworths, 1981, p. 297.

[25] Alec Groysman, Corrosion for Everybody. Springer, 2010, pp. 35-36. 